\title{
Glycophenotype of squamous epithelia: from laboratory to clinical practice
}

\author{
Karel Smetana Jr. \\ Charles University, $1^{\text {st }}$ Faculty of Medicine, Institute of Anatomy and $2^{\text {nd }}$ Faculty of Medicine, Center of Cell \\ Therapy and Tissue Repair, Praha, Czech Republic
}

\begin{abstract}
Summary
The epidermal stem cell plays a pivotal role in the function of squamous epithelia in physiological as well as in pathological conditions such as cancer. This review summarizes data about the glycobiology of normal squamous epithelia and related tumors with respect to epithelial cell differentiation and search for a glycophenotype specific for epidermal stem cells using labeled plant and endogenous lectins. Although the glycophenotype typical for epithelial cells at the stage of low differentiation level were found, no typical cell surface saccharidic markers of stem cells were detected. The nuclear binding of galectin-1 seems to be specific for the keratinocyte population prepared from hair follicles enriched for multipotent stem cells. The close topographical relationship of nuclear galectin-1 binding sites with SC35 splicing factor suggests some role for these glycoepitopes in pre-mRNA splicing. The data shown in this paper can be employed for diagnostic purposes and for cell therapy of skin defects and indicate the importance of the use of endogenous lectins as probes in biology and medicine.
\end{abstract}

Keywords: epidermal stem cell - glycocode - endogenous lectin-galectin-carcinoma

\section{SQUAMOUS EPITHELIA AS STRATIFIED TISSUES}

Squamous epithelium (epidermis, oral mucosa, cornea) is an example of differentiation-dependent and functionally stratified epithelium. Although the structure of epithelium depends on the distinct location, the general structure is the same. The proliferation active cells are located in the basal layer and the direction of differentiation of cells has a gradient from the basal to the last suprabasal layer of epithelium. The basal cells are anchored to the basement membrane by hemidesmosomes and they are able to actively migrate. These cells express receptors of the integrin type and distinct representatives of intermediate filaments as the main cytoskeletal elements. The intercellular contacts of desmosomal type are typical for suprabasal cells. These cells also lack migration potential. They are passively moved to the epithelium surface and cytokeratin 10 represents the main representative of intermediate filaments. The suprabasal cells of cornifying epithelia (epidermis) also express the specific proteins (for example involucrin) forming the cornified envelopes in these cells (for review see Kanitakis 2002).

\section{EPIDERMAL STEM CELL}

The epidermal stem cell (ESC) is an example of so called organ stem cells. ESCs have nonlimited mitotic activity. They are located in the bulge region of the sheath of hair follicle and according to other authors also in the basal layer of the interfollicular epidermis. ESCs of corneal epithelium are selectively located in the epithelium covering the limbus. Generally, ESCs are located deeply in the epithelium to be protected against damage of DNA by ultraviolet irradiation (Lavker and Sun 2000, Watt 2002). ESCs seem to be multipotent such was demonstrated using the model of injection of green fluorescent protein transfected newborn ESCs into 

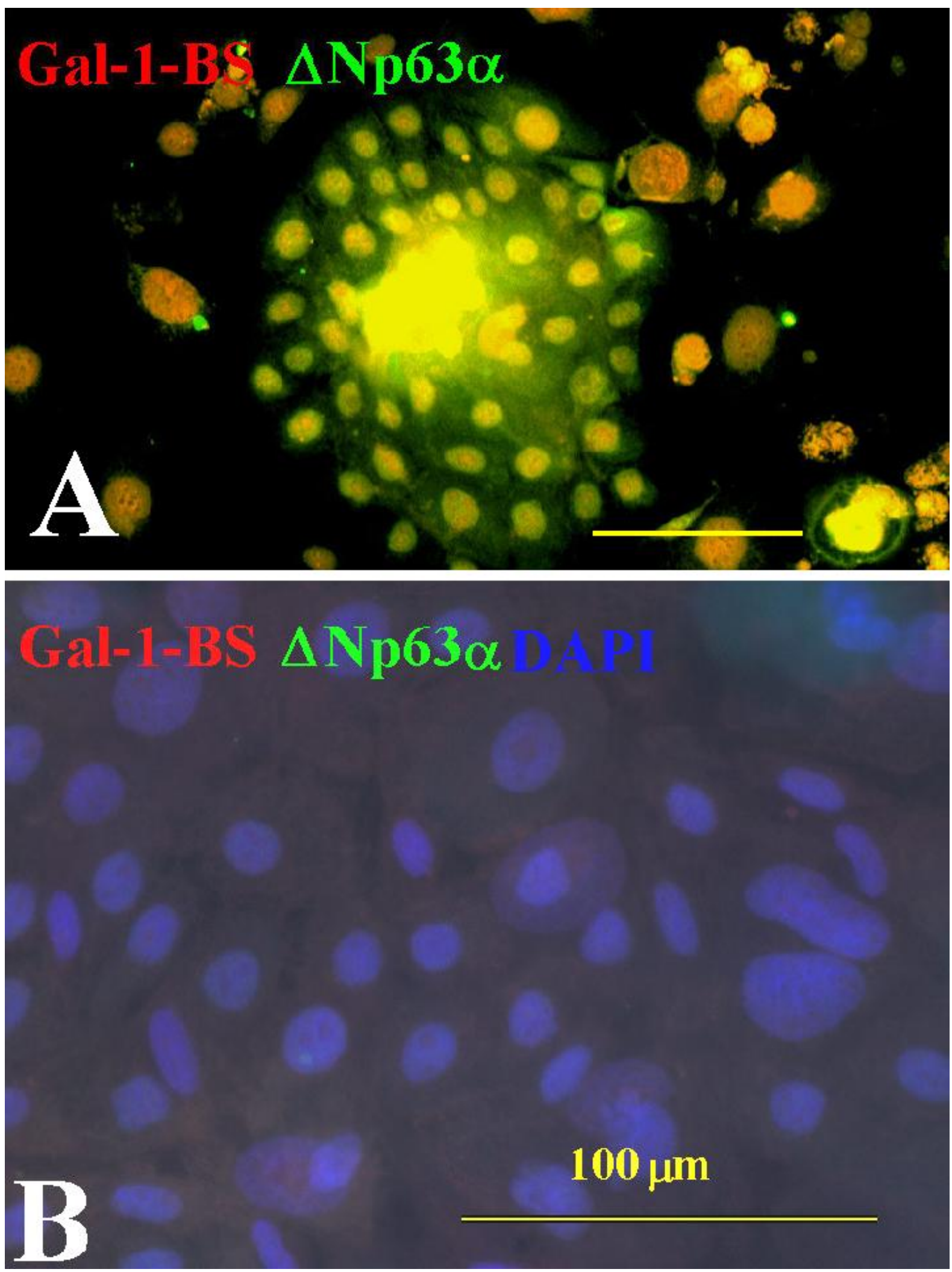

Fig. 1. Nuclei of cultured keratinocytes of hair follicle origin (A) express galectin-1-binding sites (red signal) and $\Delta \mathrm{Np63 \alpha}$ (green signal) in contrast to cells of interfollicular nature (B). Colocalization of both markers is yellow. Nuclei in specimen B were counterstained with DAPI. Bar is $100 \mu \mathrm{m}$. 
the mouse blastocysts (Liang and Bickenbach 2002). ESCs are able to divide by asymmetric mitosis. The first daughter cell has again properties of ESC, the second one (transit amplifying cell) has restricted mitotic activity. The molecular control of the ESC phenotype maintenance is not well understood but the Sonic hedgehog (Shh) gene signalization cascade seems to have some role in this mechanism (Chiang et al. 1999). This idea is well supported by observations of Shh mutations in basal cell carcinomas of the skin (Fan et al. 1997). In contrary, $c-m y c$ activity is involved with the transit amplifying cell phenotype (Gandarillas and Watt 1997). No specific phenotypic marker of ESC is known. $\beta_{1}$ integrin highly positive cells seem to have properties of ESC. However, the difference in the positivity of all cells in the basal layer or cells in the bulge region is not so remarkable. The expression of specific cytokeratins (type 15 and 19) is also not so specific (Lavker and Sun 2000, Watt 2002). A member of the protein p53 family known as $\Delta \mathrm{Np} 63 \alpha$ expression was described in the nuclei of ESCs (Pellegrini et al. 2001). However, further work in verification of this marker validity is necessary. Some slowly proliferating cells of mouse hair follicle express cytokeratins and CD34 (Trempus et al. 2003). This molecule is, therefore, also a candidate for the marker of ESC. The absence of a specific cell surface ESC marker is a great disadvantage because selective separation and cultivation of ESCs is problematic.

\section{GLYCOCODE}

Monosaccharides polymerize into the highly variable chains, although the monomer number is limited. The distinct saccharidic motifs are selectively recognized with lectins, proteins different from enzymes and immunoglobulins. The saccharide oligo-/polymers can be considered for the data storage medium, which is decoded by lectins and the term glycocode was published (Gabius et al. 2002). Higher animals including humans express 5 classes of lectins (endogenous lectins) among them galectins play an important role. This lectin family recognizes $\beta$-galactosides and histo-blood A/B trisaccharides (galectin-3). Their activity is not conditioned by the presence of divalent cations. Galectins participate in the intercellular and cell-extracellular matrix interaction. Galectin- 1 and -3 have some role in the control of proliferation/apoptosis and splicing of pre-mRNA (Gabius 1997).

\section{GLYCOBIOLOGY OF SQUAMOUS EPITHELIA in situ AND in vitro}

Galectin-3-reactive epitopes are expressed by suprabasal keratinocytes of epidermis, cornea and oral or laryngeal mucosa. These epitopes are localized on the cell surface and colocalize with desmosomal proteins desmoplakin and desmoglein. Galectin-3-binding cells express cytokeratin 10. No expression of the proliferation marker Ki-67 and $\beta_{1}$ integrin was detected in galectin-3-reactive cells. Galectin-1-reactive epitopes expression is not dependent on the level of epithelial cell differentiation, and cytoplasmic signal of galectin1-binding sites was detected in the cells occurring basally and suprabasally (Plzák et al. 2001, Plzák et al. 2002). Cultured keratinocytes prepared from hair follicle express intranuclear galectin-1-binding sites, which colocalize with $\Delta \mathrm{Np} 63 \alpha$ protein. No similar phenomenon was observed in cultured cells of interfollicular origin (Fig. 1). The basal cells of epithelia contain $\alpha 2,6$ isomer of $\mathrm{N}$-acetylneuraminic acid (Sambucus nigra agglutinin-reactive) and these cells are reactive for galectin-3 after removal of this moiety by neuraminidase. Expression of $\alpha 2,3$ isomer of $\mathrm{N}$-acetylneuraminic acid (reactive for plant lectin Maackia amurensis isoagglutinin 2) has no effect on galectin-3 binding to epithelial cells (Holíková et al. 2002). Expression of $\alpha-\mathrm{N}$ acetylgalactosamine (reactive for plant lectin Dolichos biflorus agglutinin) is connected with the accumulation of $\beta_{1}$ integrin in ERGIC (endoplasmic reticulum Golgi intermediate complex), and migration of basal cells suprabasally is connected with this process (Dvořánková et al. 2002). Basal cells of the epidermis recognize mannose-rich oligosaccharides of laminin and immobilization of mannosides to synthetic surfaces is suitable for cultivation of keratinocytes without feeder cells (Labský et al. 2003). The use of this new cultivation support for direct grafting of cultured keratinocytes to the wound bed would be possible. Nuclear expression of galectin-1-reactive epitopes in cultured keratinocytes (Fig. 1) seems to be one of the potential markers of epidermal stem cells and these galectin-1-binding sites have a positional relation to the expression of splicing factor SC35, which indicates some role in pre-mRNA splicing (unpublished results).

\section{GLYCOBIOLOY OF EPIDERMAL AND HEAD AND NECK CARCINOMAS}

Basal cell carcinomas exhibited binding sites for galectin-1, but they were not recognized with 
galectin-3. Poorly differentiated cells of head and neck squamous cell carcinomas were also negative for the occurrence of galectin-3-binding sites, which were expressed in more differentiated cells (Plzák et al. 2000, Plzák et al. 2001). The binding of galectin-3 to poorly differentiated tumor cells was restored by neuraminidase pretreatment (Holíková et al. 2002). These results indicate the possibility of using labeled endogenous lectins as a tool for diagnostic purposes.

\section{CONCLUSION}

Data presented in this review show the glycobiology of epithelial tissue as a highly prospective field of cell biology with the possibility of direct employment in histopathology and cell therapy.

\section{ACKNOWLEDGEMENTS}

This study was supported with Ministry of Education, Youth and Sport of the Czech Republic, projects No. MSM111100005, LN 00A065, Academy of Sciences of the Czech Republic, project No S4050005 and Grant Agency of the Czech Republic, project No 304/02/0463.

Received 30 ${ }^{\text {th }}$ May 2003.

Published online $8^{\text {th }}$ July 2003.

Simultaneously published in J. Berger (ed): Advances in Cell Biology. Kopp Publ., České Budějovice 2003, pp. 127-135.

\section{REFERENCES}

Chiang C., R.Z. Swan, M. Gratchouk M. Bolinger, Y. Litingtung, E.K. Robertson, M.K. Cooper, W. Gaffield, H. Westphal, P.A. Beachy, A.A. Dlugosz: Essential role for sonic hedgehog during hair follicle morphogenesis. Develop. Biol. 205: 1-9, 1999.

Dvořánková B., J. Motlík, Z. Holíková, J. Vacík, K. Smetana Jr.: Dolichos biflorus agglutininbinding site expression in basal keratinocytes is associated with cell differentiation. Biol. Cell 94: 365-373, 2002.

Fan H.R., A.E. Oro, M.P. Scott, P.A. Khavari: Induction of basal cell carcinoma features in transgenic human skin expressing Sonic Hedgehog. Nature Med. 3: 788-792, 1997.

Gabius H.-J.: Animal lectins. Eur. J. Biochem. 243: 543-576, 1997.

Gabius H.-J., S. André, H. Kaltner, H.-C. Siebert: The sugar code: functional lectinomics. Biochim. Biophys. Acta 1572, 165-177, 2002.

Gandarillas A., F.M. Watt: c-Myc promotes differentiation of epidermal stem cells. Genes Dev. 11: 2869-2882, 1997.

Holíková Z., E. Hrdličková-Cela, J. Plzák, K. Smetana Jr., J. Betka, B. Dvořánková, M. Esner, K. Wasano, S. André, H. Kaltner, J. Hercogová, R. Kodet, H.-J. Gabius: Defining the glycophenotype of squamous epithelia by plant and mammalian lectins. Differentiationdependent expression of $\alpha 2,6$ - and $\alpha 2,3$ - linked $\mathrm{N}$-acetylneuraminic acid in squamous epithelia and carcinomas and its differential effect on binding of the endogenous lectins galectin-1 and -3. APMIS 110: 845-856, 2002.

Kanitakis J.: Anatomy, histology and immunohistochemistry of normal human skin. Eur. J. Dermatol. 12: 390-401, 2002.

Labský J., B. Dvořánková, K. Smetana Jr., Z. Holíková, L. Brož, H.-J. Gabius: Mannosides as crucial part of bioactive support for cultivation of human epidermal keratinocytes without feeder cells. Biomaterials 24: 863-872, 2003.

Lavker R.M. and T.-T. Sun: Epidermal stem cells: Properties, markers, and location. Proc. Natl. Acad. Sci. USA 97: 13473-13475, 2000.

Liang L. and J.R. Bickenbach: Somatic epidermal stem cells can produce multiple cell lineages during development. Stem Cells 20, 21-33, 2002.

Pellegrini G., E. Dellambra, O. Golisano, E. Martinelli, I. Fantozzi, S. Bondanza, D. Ponzin, F. McKeon, M. De Luca: p63 identifies keratinocyte stem cells. Proc. Natl. Acad. Sci. USA 98: 3156-3161, 2001.

Plzák J., K. Smetana Jr., J. Betka, R. Kodet, H. Kaltner, H.-J. Gabius: Endogenous lectins (galectin-1 and -3) as probes to detect differentiation-dependent alterations in human squamous cell carcinomas of the oropharynx and larynx. Int. J. Mol.. Med. 5: 369-372, 2000.

Plzák J., Z. Holíková, K. Smetana Jr., B. Dvořánková, J. Hercogová, H. Kaltner, J. Motlík, H.-J. Gabius: Differentiationdependent glycosylation of cells in squamous 


\section{Glycophenotype of squamous epithelia}

cell epithelia detected by mammalian lectin. Cells Tissues Organs 171: 135-144, 2002.

Plzák J., K. Smetana Jr., E. Hrdličková, R. Kodet, Z. Holíková, F.-T. Liu, B. Dvořánková, H. Kaltner, J. Betka, H.-J. Gabius: Expression of galectin-3-reactive ligands in squamous cancer and normal epithelial cells as a marker of differentiation. Int. J. Oncol. 19, 59-64, 2001.
Trempus C.S., R.J. Morris, C.D. Bortner, G. Cotsarelis, R.S. Faircloth, J.M. Reece, R.W. Tennant: Enrichment for living murine keratinocytes from the hair follicle bulge with cell surface marker CD34. J. Invest. Dermatol. 120: 501-511, 2003.

Watt F.M.: The stem cell compartment in human interfollicular epidermis. J. Dermatol. Sci. 28: 173-180, 2002.

\section{* Address:}

Karel Smetana Jr., Charles University, $1^{\text {st }}$ Faculty of Medicine, Institute of Anatomy, U nemocnice 3 , 12800 Praha 2, Czech Republic; ksmet@lf1.cuni.cz 